\title{
Inland blue holes of The Bahamas - chemistry and biology in a unique aquatic environment
}

\author{
Caroline Björnerås ${ }^{1}$, Martin Škerlep" ${ }^{1, ~ *, ~ R a p h a e l ~ G o l l n i s c h ~}{ }^{1}$, Simon David Herzog ${ }^{1}$, \\ Gustaf Ekelund Ugge ${ }^{1,2}$, Alexander Hegg ${ }^{1}$, Nan Hu', Emma Johansson', \\ Marcus Lee ${ }^{1}$, Varpu Pärssinen', Yongcui Sha', Jerker Vinterstare ${ }^{1}$, Huan Zhang ${ }^{3}$, \\ Kaj Hulthén', Christer Brönmark ${ }^{1}$, Lars-Anders Hansson ${ }^{1}$, P. Anders Nilsson ${ }^{1,4}$, \\ Karin Rengefors ${ }^{1}$ and R. Brian Langerhans ${ }^{5}$
}

With 3 figures and 2 tables

\begin{abstract}
While lake systems in temperate regions have been extensively studied, tropical and subtropical systems have received less attention. Here, we describe the water chemistry and biota of ten inland blue holes on Andros Island, The Bahamas, representative of the morphological, abiotic, and biotic variation among Androsian inland blue holes. The majority of the studied blue holes were vertically stratified with oxic freshwater overlying anoxic saline groundwater of marine origin. Water chemistry (e.g. total phosphorus and nitrogen) in shallow waters was similar among blue holes, while turbidity and water color varied. Presence of hydrogen sulfide and reduced iron in and below the halocline indicate reducing conditions in all stratified blue holes. The biota above the halocline was also similar among blue holes with a few taxa dominating the phytoplankton community, and the zooplankton community consisting of copepods and rotifers. The Bahamas mosquitofish (Gambusia hubbsi) was present in all investigated blue holes, often accompanied by other small planktivorous fish, while the piscivorous bigmouth sleeper (Gobiomorus dormitor) was only present in some of the blue holes. Our field study reinforces that inland blue holes are highly interesting for biogeochemical research, and provide naturally replicated systems for evolutionary studies.
\end{abstract}

Keywords: Andros Island; anchialine caves; redox biogeochemistry; halocline, sub-tropical; aquatic ecosystems

\section{Introduction}

While extensive research on lake biogeochemistry has been conducted in temperate regions, less is known about sub-tropical and tropical systems (Fukushima et al. 2017). One such sub-tropical system is the unique inland 'blue holes' found throughout The Bahamas carbonate platform. Blue holes are water-filled, anchialine caves (Fig. 1) originating from periods of low sea level when dissolution of exposed carbonate bedrock resulted in caverns. Today the inland blue holes are commonly characterized by a surface freshwater layer overlying anoxic saline groundwater (Mylroie et al. 1995). Strong vertical stratification with a halo-

\section{Authors' addresses:}

${ }^{1}$ Lund University, Aquatic Ecology, Department of Biology, Lund, Sweden

${ }^{2}$ University of Skövde, School of Bioscience, Skövde, Sweden

${ }^{3}$ Chinese Academy of Sciences, Institute of Hydrobiology, Wuhan, People's Republic of China

${ }^{4}$ River Ecology and Management Research Group RivEM, Department of Environmental and Life Sciences, Karlstad University, Sweden

${ }^{5}$ North Carolina State University, Department of Biological Sciences and W.M. Keck Center for Behavioral Biology, Raleigh, USA

* Corresponding author: martin.skerlep@biol.lu.se 